MATEC Web of Conferences 21, 05006 (2015)

DOI: $10.1051 /$ matecconf $/ 20152105006$

(C) Owned by the authors, published by EDP Sciences, 2015

\title{
HFQ forming of AA6082 tailor welded blanks
}

\author{
Jun Liu, Haoxiang Gao, Omer El Fakir, Liliang Wanga , and Jianguo Lin \\ Department of Mechanical Engineering, Imperial College London, London SW7 2AZ, UK
}

\begin{abstract}
An advanced forming technology, solution Heat treatment, Forming and in-die Quenching $\left(\mathrm{HFQ}^{\circledR}\right)$, has been employed to form AA6082 tailor welded blanks (TWBs). In comparison with conventional stamping of TWBs, the mechanical properties and formability of AA6082 laser TWBs could be improved under the HFQ forming condition. The TWB was divided into three physical zones, i.e. base metal, heat affected zone (HAZ) and weld zone, based on the hardness distribution. It was found that the degraded hardness of the weldment can be restored after HFQ forming. TWBs of AA6082 with different thickness ratios of $2(2-1 \mathrm{~mm}), 1.3(2-1.5 \mathrm{~mm})$ and $1(1.5-1.5 \mathrm{~mm})$ were used to study the TWB thickness ratio effects on the forming behaviour. Hemispherical punch dome tests on the TWBs with varying thickness ratios demonstrated different formabilities, and indicated increased displacement of the weld line with increasing thickness ratio. Finite element (FE) modelling was adopted to analyse the weld line movement and strain distributions during HFQ forming.
\end{abstract}

$\mathrm{HFQ}^{\circledR}$ is a registered trademark of Impression Technologies Ltd.

\section{Introduction}

In recent decades, aluminium alloys have attracted the attention of many researchers, engineers and designers as promising structural materials for the automotive industry applications. As a commercial alloy with high stiffness to density and high strength to density ratios, AA6082 is suitable for structural sheet-metal fabrications.

Tailor welded blanks (TWBs) consisting of multiple sheet materials joined with welds has been widely used in lightweight structures. The market for aluminium alloys is expanding into various sectors, most significantly in automotive industries where the use of tailor welded blanks in aluminium is developing rapidly. Due to the development of advanced forming technologies, it is now possible to form tailor welded blanks to produce body panels with complex structure and reduced weight [1]. The most commonly used welding technology for manufacturing the AA6082 tailor welded blanks is laser beam welding. Laser welding has various advantages, including high productivity, high weld quality in terms of controllable heat affected zone (HAZ) and weld zone, low distortion, flexibility due to the movable heat source, reliability and precision [2].

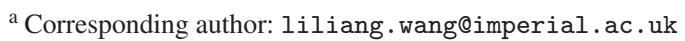

This is an Open Access article distributed under the terms of the Creative Commons Attribution License 4.0, which permits unrestricted use, distribution, and reproduction in any medium, provided the original work is properly cited. 


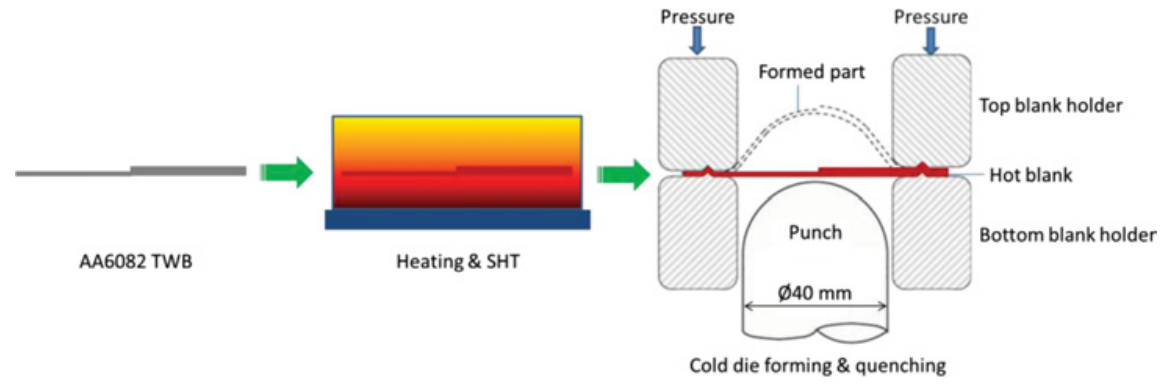

Figure 1. Schematic diagram of the HFQ forming process.

Generally, the overall formability of TWBs is significantly affected by the welding parameters [3], e.g. power source, welding speed etc., especially for heat-treatable aluminium alloys. The weld area in aluminium TWBs is typically weaker than the base material, which adds difficulty in forming such TWBs. Foster et al. [4] have developed a novel process, solution Heat treatment, Forming and in-die Quenching (HFQ), which was able to overcome the major problems in forming AA6082, such as low formability and microstructure variations.

The aim of this work is to apply the novel HFQ process into the forming of laser welded AA6082 TWBs. The degraded hardness of the TWB can be restored after HFQ forming and artificial ageing. AA6082 TWBs with different thickness combinations of 2-1, 2-1.5 and 1.5-1.5 mm were used to study the TWB thickness ratio effects on the forming behaviour. Finite element simulations were performed for evaluating the strain distributions and weld line movement during deformation.

\section{Experimental details}

The base material used in this study was the aluminium alloy AA6082-T6. The blanks (initial size of $600 \times 300 \mathrm{~mm}^{2}$ ) with thicknesses of $1,1.5$ and $2 \mathrm{~mm}$ were initially cut along the length (rolling) direction, and then welded together parallel to the rolling direction into three different thickness combinations, i.e. $2-1,2-1.5$ and $1.5-1.5 \mathrm{~mm}$ TWBs. Laser welding was carried out on the blanks using a Nd:YAG source through a $0.2 \mathrm{~mm}$ fibre with a power of $2.1 \mathrm{~kW}$. The welding speed was $25 \mathrm{~mm} / \mathrm{s}$. In this study, the investigations were focused only on butt welds with fully penetrated joints.

Hemispherical dome tests were conducted to investigate the formability of AA6082 TWBs at speeds of 75, 250 and $400 \mathrm{~mm} / \mathrm{s}$ under HFQ conditions. The tool used for the HFQ forming test is shown in Fig. 1. It comprises of the top punch pole, $40 \mathrm{~mm}$ diameter hemispherical punch, top/bottom blank holders, and the TWB. During testing, the punch was fixed, while the top blank holder was moved down at the desired rate to first clamp the TWB between the top and bottom blank holders, and then to deform the blank over the punch to the limit dome height of the TWB. Graphite grease (Omega 35) was used as the lubricant and was evenly applied to the punch surface to reduce the friction during forming. Two gas springs were utilised to maintain the blank holding force at a constant value of $20 \mathrm{kN}$. The top blank holder was specially manufactured so as to accommodate the TWBs with different thickness combinations.

All the TWBs were initially heated to $525^{\circ} \mathrm{C}$ and maintained at the temperature for $1 \mathrm{~min}$ to ensure complete dissolution of second phases during solution heat treatment. The hot TWB was then rapidly transferred to the cold die which was immediately closed to form the dome shaped component. The transfer was completed within $10 \mathrm{~s}$, during which the blank temperature decreased to around $450{ }^{\circ} \mathrm{C}$ before the forming started. 

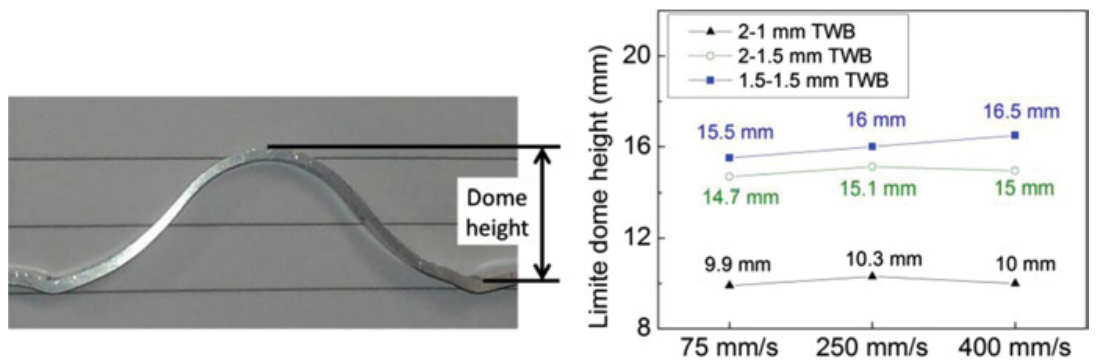

Figure 2. Limit dome height of HFQ formed tailor welded blanks.

For a sheet metal forming process, localised necking may appear at a specific forming stage just before fracture happens, which is an indication of localised plastic deformation [5]. As a stroke controlled test, the stroke of the punch was always set to a value at which localised necking was estimated to initiate, and then refined through multiple trial runs to the correct value. Due to the test piece being quite sensitive to changes in the stroke, even a small adjustment could cause fracture in the formed part. Three tests for each condition have been performed so as to ensure a good reparability of the forming results.

To determine the mechanical properties of the TWB before and after HFQ, hardness values were measured along the mid thickness of the blank using a Vickers Microhardness tester with a load of $200 \mathrm{~g}$ and a dwell time of $12 \mathrm{~s}$.

\section{Results and discussion}

\subsection{HFQ dome test}

\subsubsection{Limit dome height}

The limit dome height (LDH) is the position at which localised necking starts to occur on the formed component, and was used to compare the formability of the TWBs under HFQ conditions. In general, the LDH increases with the decreasing blank thickness ratio and increases as the forming speed increases from 75 to $400 \mathrm{~mm} / \mathrm{s}$, although the increasing trend for the $2-1 \mathrm{~mm}$ TWBs is not as significant as the 1.5$1.5 \mathrm{~mm}$ TWBs. The premature fracture occurred at higher blank thickness ratios, because the localised strain primarily occurred in the thinner blank at higher circumferential stress levels. The increase in the $\mathrm{LDH}$ with increasing forming speed is due to the enhanced strain rate hardening effect at higher forming speed. In addition, the blank temperature was higher at fast forming speed due to less heat loss into the cold punch and air, which is beneficial for the formability improvement.

\subsubsection{Deformation characteristics}

Figure 3 shows the different features of localised necking (or cracking) for the TWBs with various thickness combinations. It can be seen from Fig. 3(a) that the most severe plastic deformation occurred in the $1 \mathrm{~mm}$ blank, along the weld line. For the $2-1.5 \mathrm{~mm}$ TWB shown in Fig. 3(b), two localised thinning regions are found in mix modes combining the parallel necking and the circumferential cracking, which also corresponds to the strain distributions.

The cold die quenching was not effective due to the rough surface topography around the weld line, hence a higher blank temperature in this region has resulted in lower strength and thus fracture took place along the weld line. The circumferential necking in the thin blank was due to the stress concentration in the thinner blank, as the circumferential stress within the blank is proportional to the ratio between 

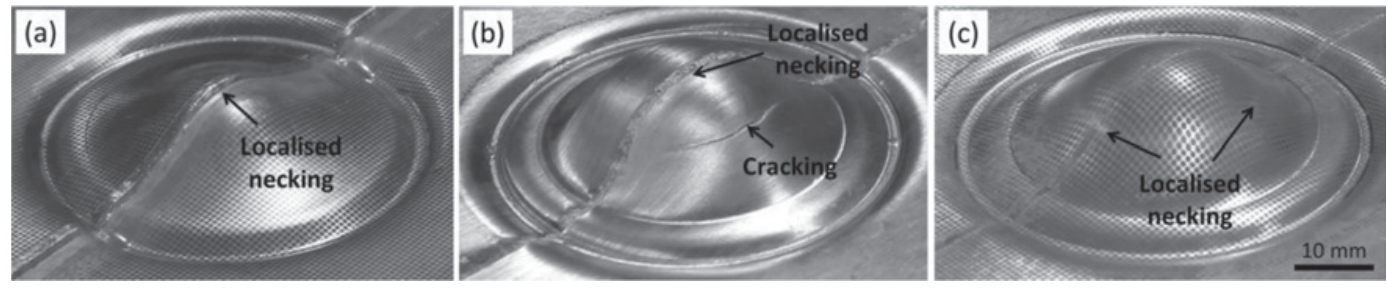

Figure 3. HFQ formed parts of (a) $2-1 \mathrm{~mm}$ TWB, (b) $2-1.5 \mathrm{~mm}$ TWB and (c) $1.5-1.5 \mathrm{~mm}$ TWB.

(a)

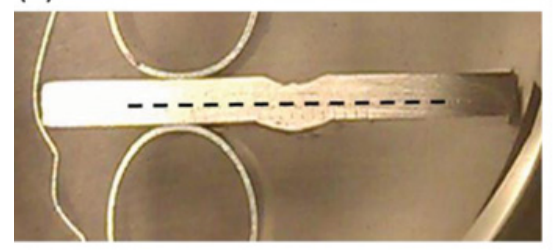

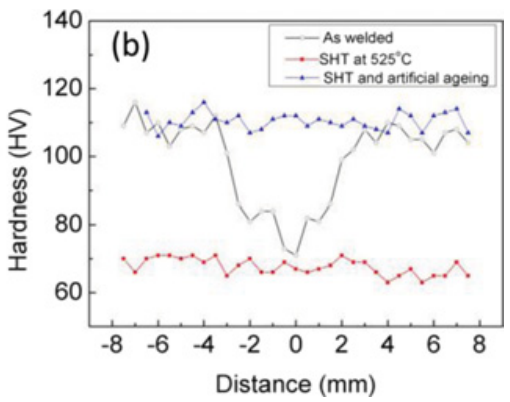

Figure 4. (a) Cross-section of a 1.5-1.5 mm TWB and (b) hardness profiles of the TWB at different heat treatment conditions.

the punch radius and blank thickness $(R / t)$. Since circumferential necking, see Fig. 3(c), occurred in the $1.5-1.5 \mathrm{~mm}$ (uniform thickness) HFQ formed part, the strain values along the cross-section exhibit a symmetric profile.

\subsubsection{Microhardness}

Microhardness values of the as-welded specimen show a typical V-shape, as plotted in Fig. 4, where the lowest value is located in the centre of the weld zone. After solution heat treatment at $525{ }^{\circ} \mathrm{C}$ and the subsequent water quenching, all the hardness decreased significantly but were at a consistent level at different measured locations. An artificial ageing treatment strengthened the material, and as a result, achieved the full hardness (HV >110) of the alloy.

\subsection{Finite element simulation}

\subsubsection{Simulation model}

Finite element (FE) simulations of the hemispherical punch forming at HFQ conditions were conducted using the commercial software PAM-STAMP and a developed temperature and strain rate dependent material model. As shown in Fig. 5, the simulation model comprises of a punch, TWB, and the blank holder sets. The tools (i.e. blank holder and punch) were modelled using rigid elements. The initial blank temperature was set to be $450{ }^{\circ} \mathrm{C}$, which is identical to the experimental condition. A friction coefficient of 0.35 was chosen to account for surface interaction between the sliding sheet and the die assembly. 


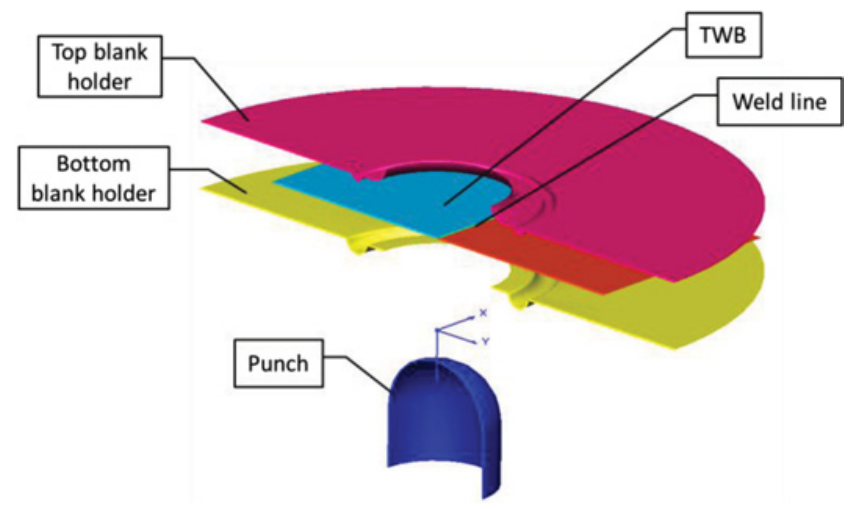

Figure 5. Pam-Stamp simulation model (cross-sectional view).
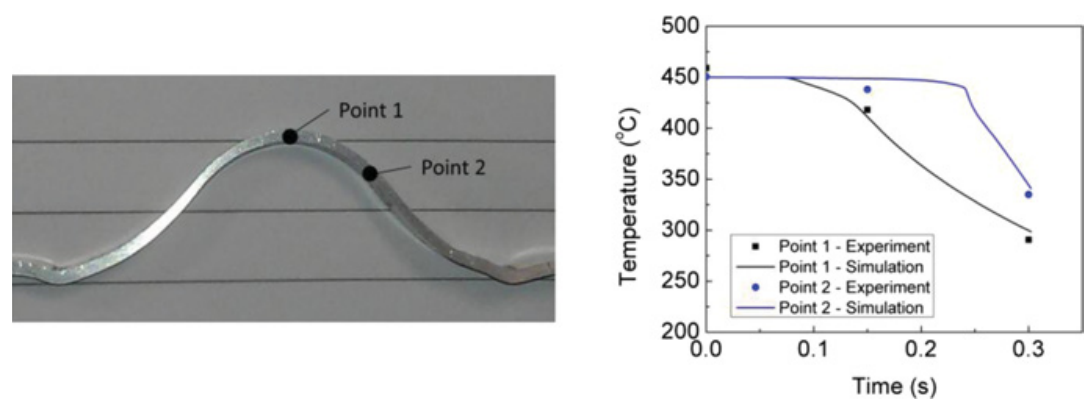

Figure 6. Temperature history during HFQ forming at $75 \mathrm{~mm} / \mathrm{s}$ between experiment and simulation.

\subsubsection{Temperature evolution}

The HFQ process is a hot sheet forming operation that incorporates part of the thermal tempering process required for heat-treatable aluminium alloys [6]. The hot blank is formed and held between cold dies, during which a rapid quenching is performed. The temperature of the deforming sheet is not uniformly distributed, which makes the deformation more complicated.

Figure 6 shows the temperature history during HFQ at a forming speed of $75 \mathrm{~mm} / \mathrm{s}$. Temperature data at two points of the formed component was recorded using a data logger at a frequency of $6 \mathrm{~Hz}$. The blank temperature was at $450{ }^{\circ} \mathrm{C}$ when the stamping started. The temperature at Point 1 dropped rapidly when the punch firstly contacted the blank at the dome apex, but there was some delayed temperature drop at Point 2 due to the later contact between this point and the punch. The predicted temperature evolution from simulation, see Fig. 6, has a good agreement with the experimental measurements.

\subsubsection{Strain distribution}

Figure 7 shows the strain comparison of the 1.5-1.5 mm TWB between experiment and simulation at the onset of localised necking. The strain distributions are able to depict deformation characteristics of this thickness combination. As shown in Fig. 3(c), the failure type was circumferential necking occurring approximately halfway between the base and apex of the formed part. As the stroke increased, the punch stretched the sheet material to a higher strain level, and the eventual failure was initiated by necking from excessive strain in a circumferential location. The good agreement between experiment and simulation 


\section{MATEC Web of Conferences}
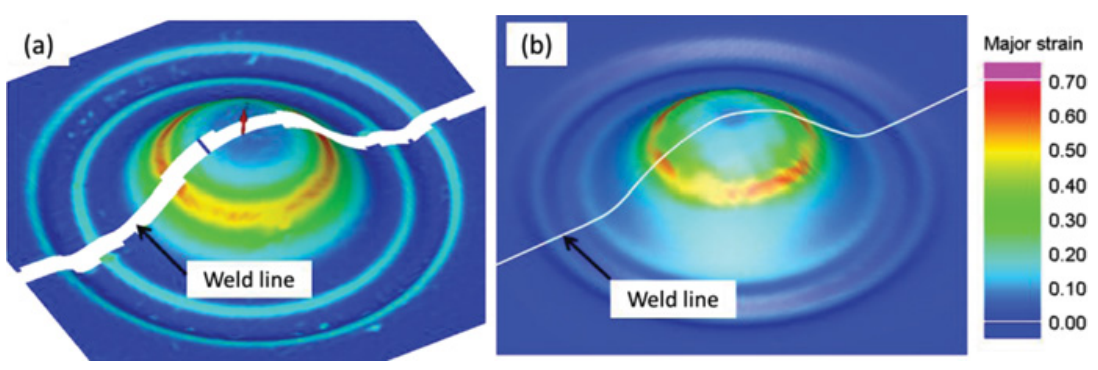

Figure 7. Comparison of strain distributions in the 1.5-1.5 mm TWB between (a) experiment and (b) simulation.

Table 1. Weld line displacement at the dome apex (unit: $\mathrm{mm}$ ).

\begin{tabular}{|c|c|c|}
\hline & Experiment & Simulation \\
\hline $2-1 \mathrm{~mm}$ TWB & 1.0 & 1.04 \\
\hline $2-1.5 \mathrm{~mm}$ TWB & 0.6 & 0.576 \\
\hline $1.5-1.5 \mathrm{~mm}$ TWB & 0 & 0 \\
\hline
\end{tabular}

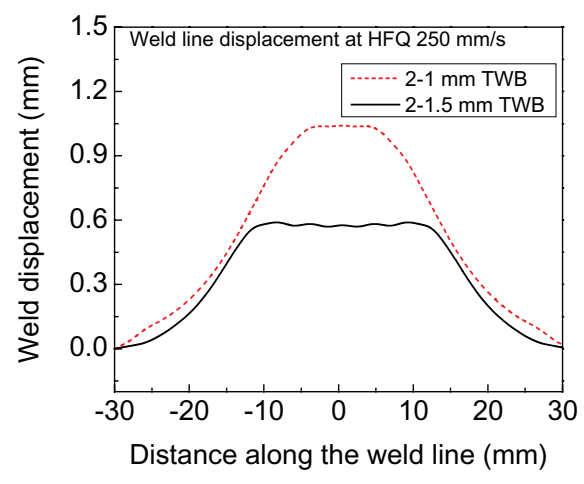

Figure 8. Predicted displacement of weld line for HFQ formed TWBs with different thickness ratios.

also indicates the feasibility of the FE simulation in prediction of the deformation behaviour, e.g. localised necking, weld line movement, etc. for other TWBs.

\subsubsection{Weld line movement}

Due to blank thickness mismatch, the weld line shifts during the dome tests of TWBs. Table 1 lists the maximum displacement of the weld in the HFQ formed TWBs with different thickness combinations. For each TWB type, the stamping stroke was maintained at the same level. It was found that the weld line displacement was nearly independent of the forming speed. Thus, only the displacement of the weld line at a forming speed of $250 \mathrm{~mm} / \mathrm{s}$ was presented here.

The weld line moves towards the thicker blank side because of the greater material flow in the thinker blank side. FE simulation is a useful method to evaluate the displacement of a whole weld line. As can be observed from Fig. 8, the weld line movement tends to increase as the thickness ratio is increased. This is because the material flow in the thicker blank is less when compared to the thinner one. It is noted that, for the predicted results in Fig. 8, the stamping stroke for each TWB type was following the experimental LDH values provide in Fig. 2. 


\section{ICNFT 2015}

\section{Conclusions}

AA6082 tailor welded blanks with various thickness combinations have been used in the HFQ forming process. The mechanical properties of the TWB have been restored after solution heat treatment, subsequent quenching and artificial ageing, indicating the advantages of the HFQ process. The HFQ formed TWBs exhibited different failure modes: localised necking parallel to the weld line for the 2-1 mm TWB, circumferential necking for the $1.5-1.5 \mathrm{~mm}$ TWB, and mixture of the parallel and circumferential necking for the $2-1.5 \mathrm{~mm}$ TWB. Thickness ratio has an important effect on the extent of the weld line movement and it was found that the weld line shift increases as the thickness ratio is increased.

The financial support from Innovate UK, Ultra-light Car Bodies (UlCab, reference 101568), is gratefully appreciated.

\section{References}

[1] R.W. Davies, H.E. Oliver, M.T. Smith, G.J. Grant, JOM 51, 46 (1999)

[2] X. Cao, W. Wallace, C. Poon, J.P. Immarigeon, Mater. Manuf. Process. 18, 1 (2003)

[3] A.A. Zadpoor, J. Sinke, R. Benedictus, Key Eng. Mater. 344, 373 (2007)

[4] A. Foster, T.A. Dean, J. Lin, Process for forming aluminium alloy sheet components 2010, European Patent EP2324137B1

[5] W.F. Hosford, Mechanical Behavior of Materials: Cambridge University Press

[6] A.D. Foster, M.S. Mohamed, J. Lin, T.A. Dean, Steel Research International 79, 133 (2009) 